\title{
EFFECTIVE THERMO-STRUCTURAL ANALYSIS FOR DISC BRAKE SYSTEM SIMULATION
}

\author{
KRAUS Pavel ${ }^{1}$, ÚRADNíČEK Juraj ${ }^{2}$, MUSIL Miloš ${ }^{1}$, BACHRATÝ Michal $^{2}$ \\ ${ }^{I}$ Slovak University of Technology in Bratislava, Faculty of Mechanical Engineering, Institute of Applied \\ Mechanics and Mechatronics, Nám. slobody 17,812 31 Bratislava, Slovakia \\ ${ }^{2}$ Slovak University of Technology in Bratislava, Faculty of Mechanical Engineering, Institute of Manufacturing \\ Systems, Environmental Technology and Quality Management, Nám. slobody 17,812 31 Bratislava, Slovakia
}

\begin{abstract}
The evaluation of disk brake squeal is nowadays performed using Finite Element Model. In this standard procedure the thermal effects are omitted. The omission is done because of long computing time of fully coupled brake system thermo-structural transient analysis. This paper is presenting an effective uncoupled thermo-structural FEM procedure. This method is applied on a pin-on-disc system and its time effectiveness is compared to standard full coupled transient analysis.
\end{abstract}

KEYWORDS: thermo-structural analysis, FEM, brake squeal

\section{Introduction}

Brake systems are one of the most important safety and performance components of vehicles as cars, trains, airplanes and industrial machines. Reliability, braking power and fluent operation are important properties of brake systems. However, during the braking the components of the disc brake tend to vibrate and the brake squeal can occur. In the last century a huge effort to understand and predict the dynamic instability was expended [1]. Nowadays it is generally accepted that brake squeal is created due to friction-induced vibration or self-excited vibration via a rotating disc [2].

The Complex eigenvalue analysis (CEVA) performed on Finite element model is the mostly used method to predict the brake squeal occurrence [4]. In the industry, the CEVA is performed on a structural model of the brake system by considering only the steady sliding state [5]. The main disadvantage of this method comparing to fully transient dynamic analysis of the system is the overprediction of the unstable states [4].

During the braking the kinetic energy of the vehicle is transformed into thermal. This heating can warm up the brake components to $400-500{ }^{\circ} \mathrm{C}$. It is important to realize three consequences of the heating and so the creation of thermal strains, the change of the coefficient of friction, which is among other things the function of the temperature and the change of heated part's material properties. For the accuracy of the instability prediction it is important to introduce these thermal effects into the FEM simulation. The thermal effects on disc brake squeal using dynamic transient and complex eigenvalue analysis was investigated by [6] and [7]. They had pointed out, that the combined transient analysis of heat conduction, contact pressure and vibration of a large FE model is difficult to perform and takes a very long time to complete.

The aim of this paper is to introduce an uncoupled thermo-structural analysis of the braking, which is not that time-consuming and can be easily added into the CEVA procedure. 


\section{Thermo-structural procedure}

In this chapter the fully coupled thermo-structural procedure and the proposed uncoupled thermo-structural procedure are introduced. Both methods are applied on the finite element (FE) model representing the experimental set-up [8] visualized in Fig. 1. This set-up was designed to study the influence of friction and contact parameters under the thermal loading.

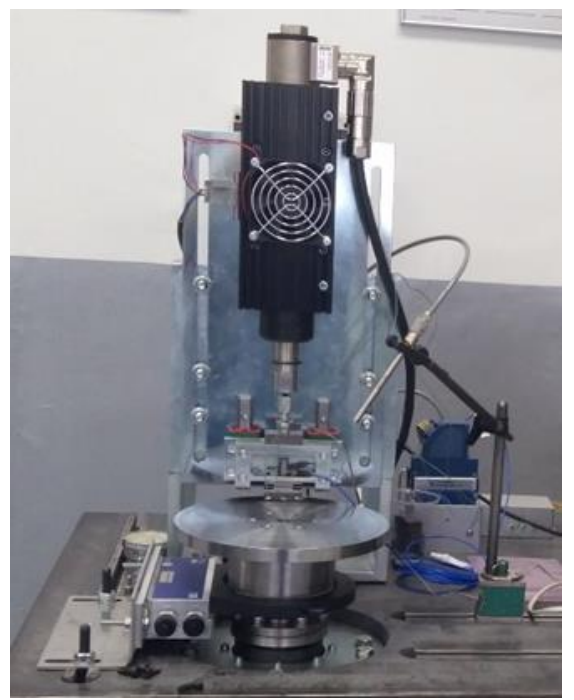

Fig. 1 Reduced pin-on-disc system

\section{Fully coupled procedure}

The heating process of the brake system is transient phenomenon, therefore to simulate this effect it is necessary to perform the transient FE analysis. The most straightforward approach is the fully coupled thermo-structural analysis.

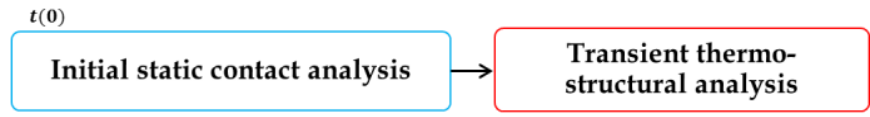

Fig. 2 Fully coupled procedure

The procedure scheme can be seen in Fig. 2. The initial static contact analysis is performed to simplify the beginning of the transient calculation. The FE nodes of the model have four degrees of freedom and do the structural displacements in three directions and temperature. During the initial static analysis, the room temperature is considered for the whole model and no heat is generated. During the second step the simulation time is divided into time steps and in every time step the dynamic and thermal balance is calculated. In this step the friction heat generation in the contact disc-pad is considered, also with strong coupling between the structural and thermal fields.

The detail description of the model boundary conditions and results are presented in the following chapters.

\section{Proposed uncoupled procedure}

The main idea to develop any modified procedure is the dynamics of the structural and thermal fields. The heating process of the brake system is a much slower act than its vibration. The results of this analysis are going to be used as input for the complex eigenvalue analysis of the system, therefore it is necessary to identify the resulting temperature field, thermal prestress of the system and contact pressure distribution. It is not necessary to calculate the 
detailed high frequency vibration of the system and so it is possible to separate the thermal and structural calculations. The chosen uncoupled procedure can be seen in Fig. 3.

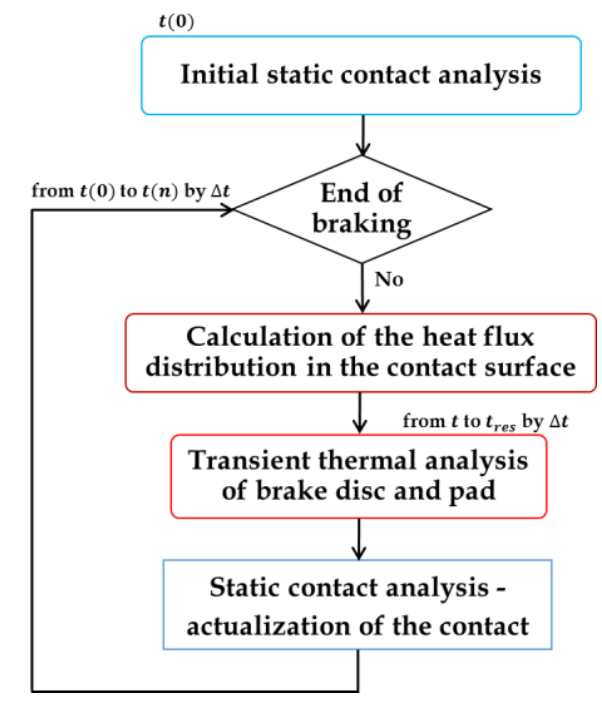

Fig. 3 Proposed uncoupled procedure

The starting step of the simulation is also initial static contact analysis. However, in this analysis only structural degrees of freedom and balance are considered. In this method there is no real rotation of the disc elements, a pseudo rotation is applied, which leads to the friction forces introduction to the system. After this step, a loop analysis is performed, containing three steps:

- 1. calculation of the heat fluxes. Heat fluxes acting on the brake pad nodes are calculated according to heat absorption $\vartheta$, friction coefficient $\mu$, contact normal forces $N$ n, radius of the node $\mathrm{r} \_\mathrm{n}$ and disc angular velocity $\omega$ by

$$
Q=\vartheta \mu N_{n} r_{n} \omega
$$

The heat fluxes acting on the disc nodes are not calculated directly from the acting contact normal forces. Firstly, the brake disc is divided into several regions in the angular direction. Secondly, the acting normal forces in every region are summed and the average value per all nodes in the regain is calculated. Then, the heat flux using (1) for every region is evaluated and applied.

- 2. thermal transient analysis. In this analysis only temperature degree of freedom and thermal balance is considered. The input for this analysis is the heat flux calculated in the previous step. In the first loop the room temperature is prescribed for each parts in the beginning. In every other loop, the last known temperature field is prescribed in the beginning.

- 3. static analysis, which works as actualization of the contact forces distribution with the consideration of the new temperature field.

The proposed solution is based on work [9] with several significant changes. In the paper [9], the temperature field on disc is calculated using $2 \mathrm{D}$ cut and then transformed into 3D model using a special time to spatial frequency transformation method. In our solution the temperature field on the brake disc is calculated using the whole 3D model using the assumption of angularly homogeneous temperature distribution. 


\section{$3 \quad$ Finite element model}

The finite element model was created in commercial program Abaqus, Fig. 4.

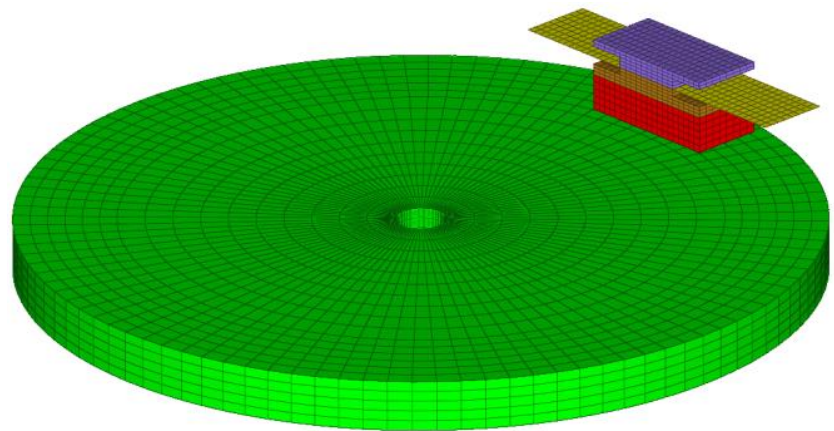

Fig. 4 FEM model of reduced pin-on-disc system consisting of brake disc - green, standard friction material FERODO - red, back plate - purple and thin plate - yellow

The applied boundary conditions (BC.) on the FE model can be seen in Fig.5. On the left side, it is possible to see the structural boundary conditions. Red area represents the contact area between the disc and the friction material, with the coefficient of friction $\mu=0.5$, and through the green areas the linear motor is pressing the pad assembly to the disc by the force $F=300 \mathrm{~N}$. The blue area represents the clamping of the disc. In the fully coupled analysis the blue area nodes are rigidly connected to each other and their rotation, $\omega=300 \mathrm{RPM}$, is prescribed. In the static analysis of the uncoupled solution, the nodes are fixed and no rotation is prescribed.
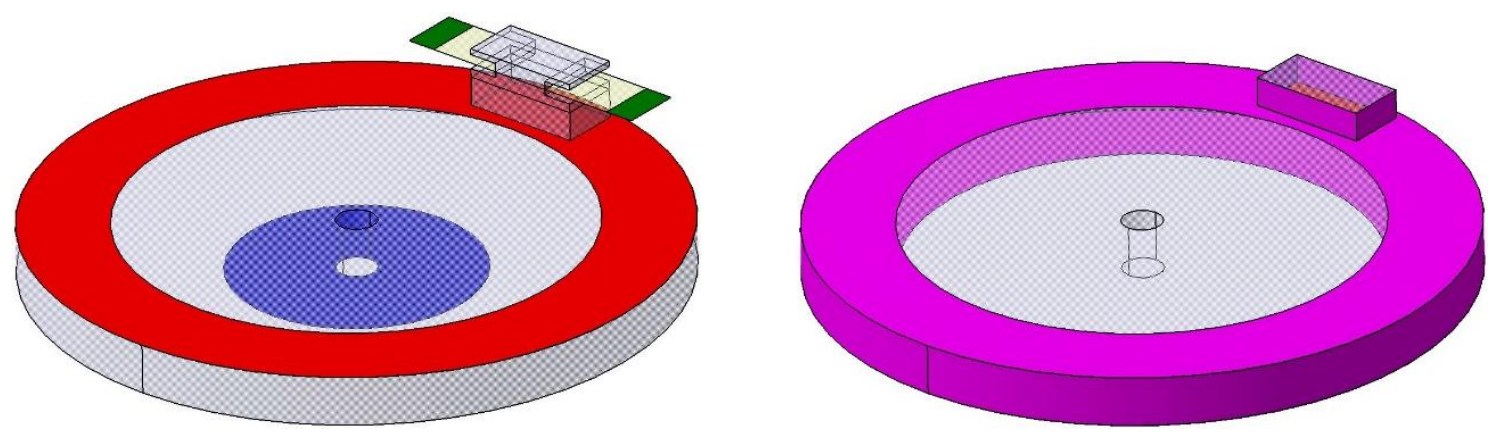

Fig. 5 Boundary conditions

The thermal $\mathrm{BC}$ consists of the initial temperature $T_{0}=25^{\circ} \mathrm{C}$, heat conductivity to the environment and heat flux generated by friction contact. The heat conductivity for the disc is prescribed on all outer areas and for the pad only for the side areas. As mentioned in the previous chapter, the heat flux generated by friction is applied for the bottom area of the pad and for the disc red area in the Fig. 5.

The end time for both simulations is $40 \mathrm{~s}$. In the case of coupled transient simulation the considered time step is $0.025 \mathrm{~s}$. This time step was chosen to have 8 steps per 1 disc rotation. In the case of thermal transient simulation, the time step is $1 \mathrm{~s}$ and the actualization of contact forces is performed every $10 \mathrm{~s}$.

\section{$4 \quad$ Results comparison}

Both simulation prescribed in Chapter 2 were performed on the same computer (Intel i7$4790 \mathrm{~K} 4 \mathrm{GHz}, 32 \mathrm{~GB}$ RAM) in program Abaqus. The comparison of these simulation results can be seen in Fig. 6. A very good match of temperature fields in time $t=40 \mathrm{~s}$ can be seen. 

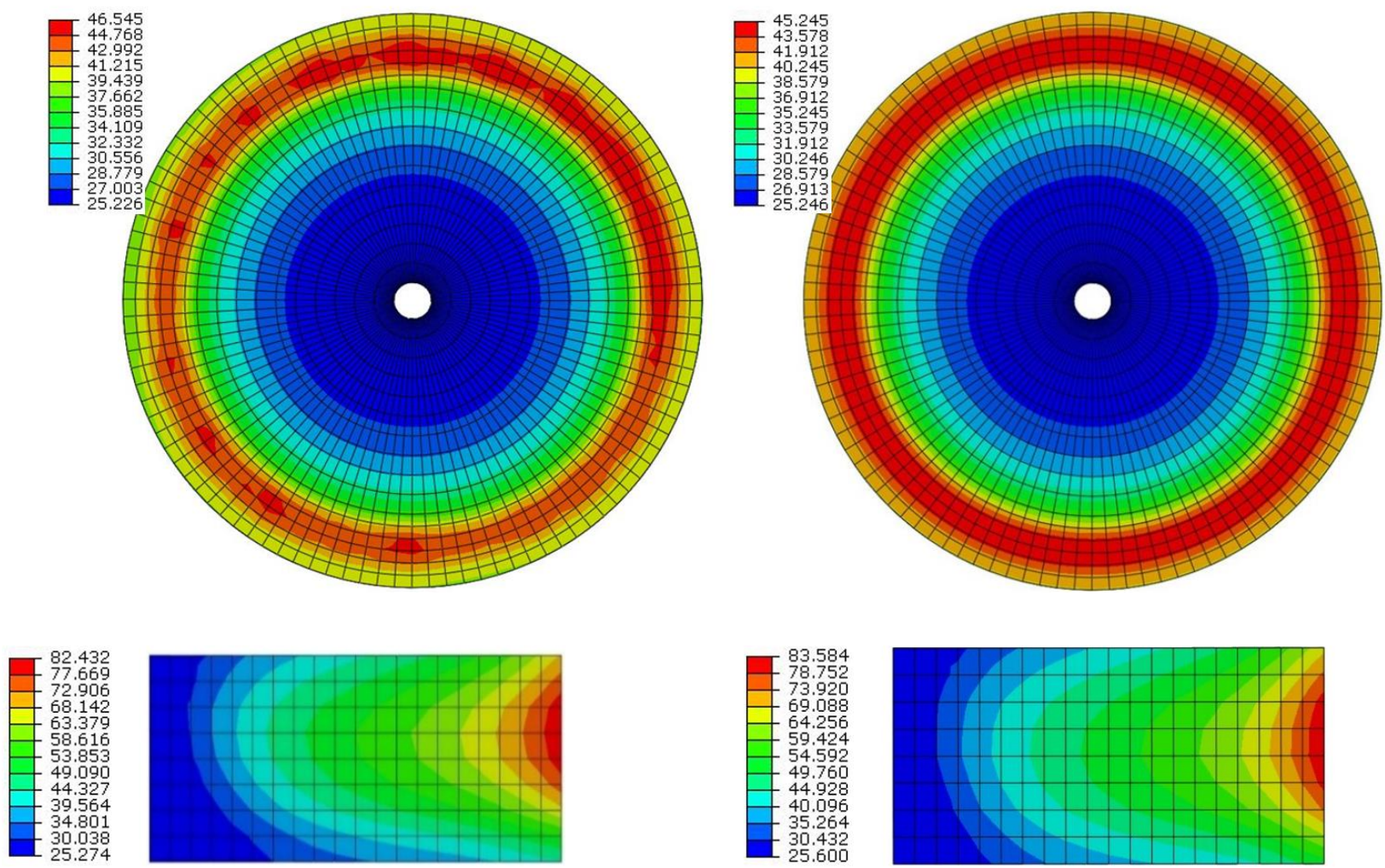

Fig. 6 Comparison of temperature fields in the end of simulation: left - coupled simulation; right - proposed solution

The results of contact stresses in time $t=40$ s on the pad side can be seen in Fig. 7. Also, in this comparison a very good match can be observed.

The simulation time of these simulations is significantly different, the fully coupled thermo-structural simulation time was $117358 \mathrm{~s}=2.05$ days, however the simulation time of proposed solution was only $307 \mathrm{~s}$. So, the proposed solution is 382 times faster.
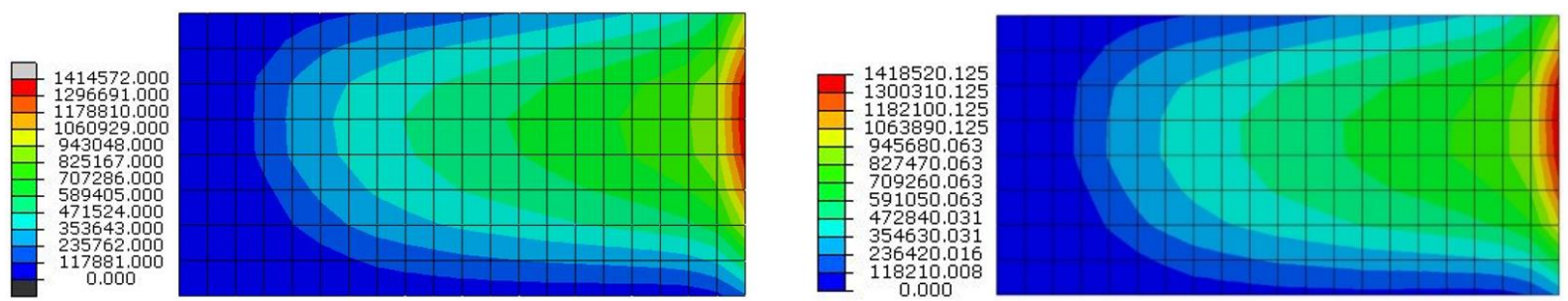

Fig. 7 Comparison of contact stresses in the end of simulation: left - coupled simulation; right - proposed solution

\section{CONCLUSION}

The proposed simulation procedure is significantly less time consuming and computationally complex compared to the full coupled transient thermo-structural analysis. The comparison of both methods shows good agreement of the results. The proposed uncoupled thermo-structural procedure will be a very effective method to introduce the thermal load into the complex eigenvalue analysis of disc brake system. In future research the method will be validated according to experimental measurements and extended with friction wear model [10]. 


\section{ACKNOWLEDGMENT}

We would like to thank company Continental Automotive Systems Slovakia s.r.o. for their support. This work was supported by the Slovak Research and Development Agency under the contract No. APVV-15-0630.

\section{REFERENCES}

[1] N. M. Kinkaid, O. M. O'Reilly, P. Papadopolous. Review of automotive disc brake squeal. Journal of Sound and Vibration 2003 (267), 105 - 166.

[2] A. R. AbuBakar, H. Ouyang. Recent Studies Of Car Disc Brake Squeal. New Research on Acoustics. Nova Science Publishers 2008, 159 - 198.

[3] J. Úradníček, P. Kraus, M. Musil, M. Bachratý. Investigation of Frictional Stick-Slick Effect in Disk Brake NVH. Journal of Mechanical Engineering - Strojnícky časopis 2017 (67), No. 1, 93 - 100.

[4] A. R. AbuBakar, H. Ouyang. Complex eigenvalue analysis and dynamic transient analysis in predicting disc brake squeal. Int. J. Vehicle Noise and Vibration 2006 (2), No. 2, $143-155$.

[5] J. Elguezabal, I. Eraña, J. M. Abete, I. Ulacia. Comparison between different complex eigenvalue strategies to reduce brake squeal overprediction. EuroBrake 2015. EB2015NVH-013. 2015.

[6] H. Ouyang, A. R. AbuBakar, L. Li. A combined analysis of heat conduction, contact pressure and transient vibration of a disc brake. International Journal of Vehicle Design, 2009 (51), No. 1, 190 - 206.

[7] M. Z. Hassan, P. C. Brooks, D. C. Barton, Thermo-Mechanical Contact Analysis of Car Disc Brake Squeal, SAE Int. J. of Passeng. Cars - Mech. Syst. 2009 (1), No. 1, 1230 1239.

[8] J. Úradníček, M. Musil, P. Peciar, M. Juhás, A. Suchal. Experimentálne testovacie zariadenie na dynamické, termálne a tribologické analýzy komponentov kotúčových bŕzd, Patent file num. 53-2015. 2017.

[9] D. Majcherczak, P. Dufrenoy. Dynamic analysis of a disc brake under frictional and thermomechanical internal loading. Archive of Applied Mechanics 2006 (75), No. 8, 497 -512 .

[10] M. Šofer, R. Fajkoš, R. Halama. Influence of Induction Hardening on Wear Resistance in Case of Rolling Contact. Journal of Mechanical Engineering - Strojnicky časopis 2016 (66), No. 1, $17-26$. 